\title{
MII Adherence to Cardiovascular Disease Medications: Does Patient-Provider Race/Ethnicity and Language Concordance Matter?
}

\author{
Ana H. Traylor, MPP'1,2, Julie A. Schmittdiel, $P h D^{3}$, Connie S. Uratsu, $B A^{3}$, \\ Carol M. Mangione, MD, MSPH ${ }^{4}$, and Usha Subramanian, $M D, M S^{5,6}$
}

'Goldman School of Public Policy, University of California, Berkeley, CA, USA; ${ }^{2}$ Care Management Institute, Kaiser Permanente, Oakland, CA, USA; ${ }^{3}$ Division of Research, Kaiser Permanente Medical Care Program, Northern California, Oakland, CA; ${ }^{4}$ Los Angeles School of Medicine and Public Health, University of California, Berkeley, CA, USA; ${ }^{5}$ Roudebush VAMC, Indianapolis, IN, USA; ${ }^{\circ}$ Division of General Internal Medicine and Geriatrics, Department of Medicine, Regenstrief Institute for Healthcare, Inc., Indianapolis, IN, USA.

BACKGROUND: Patient-physician race/ethnicity and language concordance may improve medication adherence and reduce disparities in cardiovascular disease (CVD) by fostering trust and improved patient-physician communication.

OBJECTIVE: To examine the association of patient race/ethnicity and language and patient-physician race/ethnicity and language concordance on medication adherence rates for a large cohort of diabetes patients in an integrated delivery system.

DESIGN: We studied 131,277 adult diabetes patients in Kaiser Permanente Northern California in 2005. Probit models assessed the effect of patient and physician race/ethnicity and language on adherence to CVD medications, after controlling for patient and physician characteristics.

RESULTS: Ten percent of African American, $11 \%$ of Hispanic, $63 \%$ of Asian, and $47 \%$ of white patients had same race/ethnicity physicians. $24 \%$ of Spanish-speaking patients were linguistically concordant with their physicians. African American (46\%), Hispanic (49\%) and Asian (52\%) patients were significantly less likely than white patients (58\%) to be in good adherence to all of their CVD medications $(\mathrm{p}<0.001)$. Spanish-speaking patients were less likely than English speaking patients to be in good adherence (51\% versus 57\%, p<0.001). Race concordance for African American patients was associated with adherence to all their CVD medications (53\% vs. 50\%, p<0.05). Language concordance was associated with medication adherence for Spanish-speaking patients (51\% vs. $45 \%$, $\mathrm{p}<0.05)$

CONCLUSION: Increasing opportunities for patientphysician race/ethnicity and language concordance may improve medication adherence for African American and Spanish-speaking patients, though a similar effect was not observed for Asian patients or Englishproficient Hispanic patients.

Received September 23, 2009

Revised March 13, 2010

Accepted May 10, 2010

Published online June 23, 2010
KEY WORDS: diabetes; racial/ethnic and linguistic health disparities; medication adherence; cardiovascular risk factor control; race/ethnic and language concordance; racial/ethnic minority health; medical workforce diversity.

J Gen Intern Med 25(11):1172-7

DOI: $10.1007 / \mathrm{s} 11606-010-1424-8$

(c) The Author(s) 2010. This article is published with open access at Springerlink.com

\section{INTRODUCTION}

Cardiovascular disease is the leading cause of death in the United States, and patients with diabetes are at a higher risk of CVD deaths and events than the general population ${ }^{1}$. African American, Hispanic, Native American and some Asian populations are more likely to die or have a CVD-related event than the white population, even after controlling for socioeconomic status and insurance coverage ${ }^{2}$.

Appropriate use of medications to reduce CVD risk factors has been shown to lower CVD risk factor levels and reduce CVD related deaths and events for patients with diabetes ${ }^{3}$. Adherence to medications for chronic diseases such as diabetes, hypertension and hyperlipidemia is a challenge for all patients, regardless of patient race. Approximately $10-30 \%$ of persons with type 2 diabetes have been reported to withdraw from prescribed regimens within one year of diagnosis, ${ }^{4}$ and long-term persistence in use of lipid-lowering and anti-hypertensive therapies is low ${ }^{5-7}$.

Barriers to the patient-physician relationship such as physician stereotypes and bias and disparities in the quality of interpersonal care may create even greater obstacles to medication adherence for patients of color ${ }^{8-10}$. Patients of color are more likely to face language barriers and miscommunication with their providers ${ }^{8}$ and have also have shorter and less patient centered office visits than white patients. ${ }^{10}$ Patients of color are also more likely to be negatively perceived by their physicians. Patient race is associated with physicians' assessment of patient intelligence, feelings of affiliation toward the patient, and beliefs about the patients' likelihood of risk behavior and adherence with medical advice ${ }^{11}$.

Patients are more likely to utilize services and adhere to medical advice and pharmacological regimens if they trust the health care system, feel affiliation with their providers and if 
their providers communicate effectively with them. ${ }^{12-14}$ Potentially as a response to the barriers noted above, African American and Hispanic patients are less likely to trust the medical system and more likely than whites to perceive they would have received better medical care if they belonged to a different racial and ethnic group. Patients of color are also more likely to believe that medical staff judged them unfairly or treated them with disrespect based on race and ethnicity ${ }^{15-19}$.

Physicians from racial and ethnic minority backgrounds may possess culturally specific knowledge, skills and experience that reduce barriers to the patient-physician relationship for racial/ ethnic and linguistic minority patients. ${ }^{20-22}$ Race, ethnicity and language concordance are thought to foster trust, communication and better patient-provider interaction. ${ }^{8,19}$ For example, race/ethnicity concordance is associated with higher patient ratings of physicians' participatory decision-making and higher patient satisfaction. ${ }^{8,23}$ Compared to patients whose primary physicians are of a different race/ethnicity, patients who are of the same racial or ethnic group as their physicians are more likely to use needed health services, are less likely to postpone or delay seeking care and report a higher volume of use of health services. ${ }^{24,25}$ Other studies have found that language concordance and interpreter use positively affects patients' perceived understanding of their disease and is positively associated with a range of health comes ${ }^{26,27}$.

Few empirical studies have examined or found an association between race, ethnicity or language concordance and medication adherence. $^{28}$ The purpose of this study is to examine the association between patient race/ethnicity, patient language and patient-physician race/ethnicity and language concordance on CVD risk factor medication adherence for patients with diabetes.

\section{METHODS}

\section{Study Population}

The study population consisted of a cohort of African American, Hispanic, Asian and white adult diabetes patients in Kaiser Permanente's Northern California (KPNC) Diabetes Registry who were identified as having diabetes prior to January 1, 2005 and were continuously enrolled with an active drug benefit throughout $2005^{29}$. Study participants were further assessed for hypertension and hyperlipidemia using KP automated clinical databases (See Appendix for definitions of diabetes, hypertension and hyperlipidemia). Patient demographic and clinical data was obtained through membership and clinical databases. Patient self-reported race/ethnicity and language preference was obtained from KP member surveys, study surveys and hospitalization data and was available for $87 \%$ of patients. Physician self-reported race/ethnicity and language data was obtained from physician demographic files and was available for 93.5\% of physicians. The final study population consisted of 131,277 African American, Asian, White and Hispanic adult diabetes patients and 1750 physicians. Patients with missing racial/ethnic data were excluded from the analysis.

KP Northern California members comprise approximately $25 \%$ of the adult population between 20-79 years old in Northern California and are similar in age and gender to both the insured and uninsured non KP population. Compared to non-KP insured, $\mathrm{KP}$ members are less likely to be white but similar in other characteristics. Compared to non-insured Northern Californians, KP members are more likely to be white and less likely to be very low income or to have very low levels of education. ${ }^{30}$

\section{Dependent Variables}

Treatment adherence for CVD risk factor controlling medications (diabetes, cholesterol and hypertension medications) was calculated with KP prescription databases using continuous multiple interval measures of gaps in therapy (CMG). ${ }^{31} \mathrm{CMG}$ is the proportion of days a patient was prescribed medication and did not have the medication available. For each individual condition (hyperglycemia, hypertension and hyperlipidemia), CMG was first calculated separately for each medication class filled at least twice in the 12 months prior to the last date when above target levels were observed in 2005. Individual class adherence was then combined into a single measure for all medications prescribed for a single condition, weighting the estimate for each medication class by the number of days from the first to last fill in the 12 month period. Medications filled only once were not included in the analysis because CMG can not be calculated from single fills. Because many prior studies have found significant clinical effects when cumulative days of refill gaps equal or exceed $20 \%,{ }^{31}$ we defined good adherence for each condition as a non-adherence measure less than $20 \%$. Individual condition adherence was then combined into a single measure of adherence for all medication classes a patient was prescribed for diabetes, hypertension and/or hyperlipidemia. Patients who had $80 \%$ of their medications available for each condition for which they were being treated were coded as 1 . Patients who had less than $80 \%$ of their medications available for any condition were coded as 0 .

\section{Main Explanatory Variables}

Self-reported patient race/ethnicity was the main explanatory variable for multivariable models that assessed predictors of medication adherence with white patients as the reference group. Patient-physician race/ethnicity concordance was defined as the patient and primary care provider/physician being from the same racial/ethnic background. The patients' primary care provider was defined as the physician linked to the patient the most months in 2005. It is important to note that linguistic, national background, immigrant status, acculturation and cultural diversity exists within each racial and ethnic category. We were unable to assess concordance beyond broad racial/ethnic categories.

Patient preferred language was obtained through patient selfreport. Three percent of patients in the study report a preferred language other than English. Of these patients the majority prefer Spanish (55\%) followed by Cantonese (12\%). Patients from other language backgrounds made up the remaining 33\% of patients with primary language other than English. Patientphysician Spanish language concordance was defined as the patient reporting Spanish as the preferred language spoken and the physician reporting Spanish language fluency. Physician language proficiency was obtained through physician self-report at the onset of employment with the medical group. Because less than $1 \%$ of African American and less than $2 \%$ of white patients report a primary language other than English, our Spanish language analyses focus on Hispanic patients (23\% of Hispanic patients report Spanish as their primary language). Due to language diversity and small sample sizes within language 
subgroups for Asian patients, we were unable to conduct a language concordance analysis for Asian patients.

\section{Multivariate Analyses}

Probit models were constructed to assess the marginal effect of patient race on adherence to CVD medications (hypoglycemic, lipid lowering, and anti-hypertensive medications). Probit analyses, stratified by patient race/ethnicity, examined the effect of race/ethnicity concordance on medication adherence to all CVD medications and for each condition. All models adjusted for patient clustering within physician panels. From these models we calculated the predicted percentage of patients in good adherence by patient race/ethnicity, patient preferred language and patient-physician race/ethnicity and language concordance. All models controlled for patient demographics (age, gender, language, and U.S census 2000 geocoded education and income) as well as measures of health status and utilization (number of comorbid conditions, number of primary care visits in 2005, Medicare status, and number of medication classes across the three conditions). The models also controlled for physician age, gender, language proficiency, panel size and number of diabetic patients in panel as fixed effects. All analyses were performed using STATA version 10. This study was developed and approved by the Steering Committee of the Translating Research in Action for Diabetes (TRIAD) Study, and approved by the KPNC Institutional Review Board.

\section{RESULTS}

\section{Patient and Physician Characteristics}

Most patients in the sample (94\%) were being treated for more than one CVD risk factor and almost three-quarters of patients $(72 \%)$ were being treated for all three conditions (diabetes, high cholesterol, and hypertension). Almost half of the patients
(46\%) were White, 16\% Asian, 11\% Hispanic and 10\% were African American. Almost 97\% of patients reported speaking at least some English. Spanish was the preferred language of almost a quarter (23\%) of Hispanic patients. Physicians were disproportionately White (47\%) or Asian (40\%). Less than $8 \%$ of physicians were either African American or Hispanic. While almost a quarter of physicians (23\%) reported proficiency in a non-English language, less than $5 \%$ of physicians spoke Spanish. African American and white patients had longer relationships with their physicians (6.3 years for African American and 6.1 for white patients) than Asian and Hispanic patients (5.9 for Asian and 5.6 for Hispanic patients). Spanishspeaking patients had the shortest relationship with their physicians ( 4.5 years). (Table 1 )

\section{Concordance by Patient Race/Ethnicity and Language}

Asian patients were most likely to be race concordant with their providers (63\%), followed by white patients $(47 \%)$, Hispanic patients (11\%), and African American (9.7\%) patients. Twenty-four percent of Spanish-speaking patients were linguistically concordant with their physicians.

\section{Medication Adherence by Patient Race/Ethnicity and Language}

After adjusting for patient and physician characteristics, African American, Hispanic and Asian patients were significantly less likely than white patients to be good adherence to all of their CVD risk factor controlling medications (Table 2). Spanish-speaking patients were less likely than English speaking patients to be in good adherence (51\% versus $57 \%$, $\mathrm{p}<0.001)$. The results of analyses that examined adherence for each condition/risk factor separately were significant and in the same direction as our combined measure of adherence to CVD medications.

Table 1. Patient Characteristics by Patient Race/Ethnicity

\begin{tabular}{|c|c|c|c|c|c|c|}
\hline $\begin{array}{l}\text { Patient Demographic } \\
\text { Characteristics }\end{array}$ & $\begin{array}{l}\text { African } \\
\text { American } \\
n=15,905(\%)\end{array}$ & $\begin{array}{l}\text { Hispanic } \\
n=17,750(\%)\end{array}$ & $\begin{array}{l}\text { White } \\
n=74,900(\%)\end{array}$ & $\begin{array}{l}\text { Asian } \\
\mathrm{N}=22,722(\%)\end{array}$ & $\begin{array}{l}\text { Preferred } \\
\text { language } \\
\text { is Spanish } \\
\mathrm{N}=6,712(\%)\end{array}$ & P-value* \\
\hline Age (Mean) & 60.8 & 60.1 & 63.8 & 60.1 & 56.8 & $(<0.001)$ \\
\hline Male & 45 & 50 & 52.6 & 49.2 & 50.9 & $(<0.001)$ \\
\hline Female & 55 & 50 & 47.4 & 50.8 & 49.1 & $(<0.001)$ \\
\hline English not primary language & 0.7 & 22 & 1.5 & 10.2 & 100 & $(<0.001)$ \\
\hline Median household income (Geocoded)** & $\$ 50,371$ & $\$ 55,956$ & $\$ 61,712$ & $\$ 68,016$ & $\$ 51,709$ & $(<0.001)$ \\
\hline \% College Degree in census block (Geocoded)* ** & 15.3 & 15 & 19.5 & 21.7 & & $(<0.001)$ \\
\hline \multicolumn{7}{|l|}{ Physician Race } \\
\hline African American & 9.7 & 3.4 & 3.3 & 2.2 & 3.2 & $(<0.001)$ \\
\hline Hispanic & 3.7 & 11.2 & 4.4 & 2.5 & 25.3 & $(<0.001)$ \\
\hline White & 40.4 & 35.6 & 47.4 & 31.5 & 34.9 & $(<0.001)$ \\
\hline Asian & 44 & 46.3 & 41.7 & 63.2 & 36.1 & $(<0.001)$ \\
\hline \multicolumn{7}{|l|}{ Health Status Variables } \\
\hline \# of visits (Mean) & 6.4 & 6.2 & 6.3 & 5.3 & 5.7 & $(<0.001)$ \\
\hline \# of years with physician & 6.3 years & 5.6 years & 6.1 years & 5.9 years & 4.5 years & $(<0.001)$ \\
\hline \# Comorbid conditions (Mean) & 2.7 & 2.5 & 2.8 & 2.4 & 2.2 & $(<0.001)$ \\
\hline Pill burden (Total number of drug classes) & 8.3 & 7.4 & 8.2 & 7.6 & 5.9 & $(<0.001)$ \\
\hline
\end{tabular}

*P-values represent the significance of one-way ANOVA or chi-square tests of group differences

**Median household income variable is the geocoded median household income for the population over 25 years old in the census block where a patient lives

${ }^{* * *}$ Geocoded education is the percent of the population over 25 years old with a college degree in the census block where a patient lives 
Table 2. Adjusted Adherence to CVD Medications by Patient Race

\begin{tabular}{|c|c|c|c|c|c|}
\hline & $\begin{array}{l}\text { Black Patients \% } \\
\text { (p-value) }\end{array}$ & $\begin{array}{l}\text { Hispanic Patients \% } \\
\text { (p-value) }\end{array}$ & $\begin{array}{l}\text { Asian Patients \% } \\
\text { (p-value) }\end{array}$ & $\begin{array}{l}\text { White Patients \% } \\
\text { (p-value) }\end{array}$ & $\begin{array}{l}\text { Spanish-speaking } \\
\text { Patients \% ( } p \text {-value) }\end{array}$ \\
\hline $\begin{array}{l}\text { Glucose lowering } \\
\text { medications }\end{array}$ & $74.2(<.001)$ & $75(<0.001)$ & $77.1(<0.001)$ & 82 (reference) & $76(<0.001)$ \\
\hline $\begin{array}{l}\text { Lipid Lowering } \\
\text { Medications }\end{array}$ & $75(<0.001)$ & $75.2(<0.001)$ & $77(<0.001)$ & 81.3 (reference) & $77.3(<0.001)$ \\
\hline $\begin{array}{l}\text { BP lowering } \\
\text { Medications }\end{array}$ & $74.4(<0.001)$ & $77.4(<0.001)$ & $78.5(<0.001)$ & 81.7 (reference) & $78.7(<0.001)$ \\
\hline All CVD Medications & $46(<0.001)$ & $49.4(<0.001)$ & $52.2(<0.001)$ & 57.8 (reference) & $50.7(<0.001)$ \\
\hline
\end{tabular}

All adjusted analyses significant at the $p<0.001$ level

Models adjusted for patient age, gender, preferred language, number of comorbidities, \# of primary care visits in 2005, Medicare status, \# of medication classes taken for condition, pill burden, geocoded education and income, physician age, gender, race, language, panel size and \# of diabetic patients in panel

\section{Medication Adherence by Race/Ethnicity and Language Concordance}

After adjusting for patient and physician characteristics, race/ ethnicity concordance for African American patients was marginally associated with good combined adherence to all risk factor medications for which a patient was being treated (53 vs. 50, p<0.05) (Table 3). Language concordance was associated with improved medication adherence for Hispanic patients $(51 \%$ vs. $45 \%$, p-value<0.05). Race/ethnicity concordance was not significantly associated with adherence to CVD medications for white, Asian or Hispanic patients. While in the same direction, these results were insignificant when each condition/risk factor was assessed separately.

\section{DISCUSSION}

Patient race/ethnicity and language were significant predictors of adherence to CVD risk factor medications for patients in this study. African American, Hispanic and Asian patients were less likely to adhere to CVD medications than white patients. Multiple factors may explain these disparities including differences in attitudes and beliefs about medication, ${ }^{32}$ differences in socioeconomic status that might influence affordability of drug regimens, ${ }^{33}$ differences in interpersonal care that may influence patient behavior, ${ }^{8-10}$ language and communication barriers ${ }^{11}$ and different levels of trust in physicians and/or the health care system. ${ }^{19,34}$ However, it is interesting to note that even in a managed care system with similar drug benefits, racial disparities in adherence to medications remain, suggesting that factors beyond socio-economic status play a very important role in medication adherence for chronic illness.

Patient-physician race/ethnicity concordance was not significantly associated with adherence for white patients. Given that white patients are less likely to face cultural and language barriers in the medical system, this finding is not surprising. Contrary to the race/ethnicity concordance hypothesis, however, Hispanic and Asian concordance were also not associated with good adherence. This too is not entirely surprising, given the diversity within all racial and ethnic groups, and particularly within the Hispanic and Asian populations. Primary language spoken, dialect, level of acculturation and cultural differences among patients from different national backgrounds within each racial and ethnic group may mask concordance effects.

Our findings on language concordance suggest that language concordance influences medication adherence, but we cannot ascertain whether concordance effects occur because

Table 3. Adjusted Adherence to CVD Medications by Patient Race/Ethnicity and Language Concordance

\begin{tabular}{|c|c|c|c|c|c|c|c|c|c|c|}
\hline & \multicolumn{2}{|c|}{$\begin{array}{l}\text { Black Patients } \\
\% \text { (p-value) }\end{array}$} & \multicolumn{2}{|c|}{$\begin{array}{l}\text { Hispanic Patients } \\
\% \text { (p-value) }\end{array}$} & \multicolumn{2}{|c|}{$\begin{array}{l}\text { Asian Patients } \\
\% \text { (p-value) }\end{array}$} & \multicolumn{2}{|c|}{$\begin{array}{l}\text { White Patients } \\
\% \text { (p-value) }\end{array}$} & \multicolumn{2}{|c|}{$\begin{array}{l}\text { Spanish-Speaking } \\
\text { Patients \% ( } p \text {-value) }\end{array}$} \\
\hline & Black PCP & $\begin{array}{l}\text { Non-black } \\
\text { PCP }\end{array}$ & $\begin{array}{l}\text { Hispanic } \\
\text { PCP }\end{array}$ & $\begin{array}{l}\text { Non-Hispanic } \\
\text { PCP }\end{array}$ & Asian PCP & $\begin{array}{l}\text { Non-Asian } \\
\text { PCP }\end{array}$ & White PCP & $\begin{array}{l}\text { Non-white } \\
\text { PCP }\end{array}$ & $\begin{array}{l}\text { Spanish } \\
\text { Proficient } \\
\text { PCP }\end{array}$ & $\begin{array}{l}\text { Non-Spanish } \\
\text { PCP }\end{array}$ \\
\hline $\begin{array}{l}\text { Glucose } \\
\text { Controlling } \\
\text { Medications }\end{array}$ & $\begin{array}{l}79.8 \\
(0.166)\end{array}$ & 77.6 & $\begin{array}{l}76.1 \\
(0.655)\end{array}$ & 76.6 & $\begin{array}{l}82.7 \\
(0.131)\end{array}$ & 81.6 & $\begin{array}{l}85.3 \\
(0.550)\end{array}$ & 85.1 & $\begin{array}{l}77.5 \\
(0.430)\end{array}$ & 76.6 \\
\hline $\begin{array}{l}\text { Lipid } \\
\text { Lowering } \\
\text { Medications }\end{array}$ & $\begin{array}{l}79.6 \\
(0.331)\end{array}$ & 78 & $\begin{array}{l}78 \\
(0.492)\end{array}$ & 77.3 & $\begin{array}{l}80.1 \\
(0.947)\end{array}$ & 80.1 & $\begin{array}{l}84.1 \\
(0.301)\end{array}$ & 83.7 & $\begin{array}{l}80.5 \\
(0.157)\end{array}$ & 77.5 \\
\hline $\begin{array}{l}\text { BP lowering } \\
\text { Medications }\end{array}$ & $\begin{array}{l}76.6 \\
(0.98)\end{array}$ & 76.6 & $\begin{array}{l}77 \\
(0.262)\end{array}$ & 78.8 & $\begin{array}{l}82 \\
(0.570)\end{array}$ & 81.7 & $\begin{array}{l}83.6 \\
(0.081)\end{array}$ & 82.9 & $\begin{array}{l}81 \\
(0.423)\end{array}$ & 79.3 \\
\hline $\begin{array}{l}\text { All CVD } \\
\text { Medications }\end{array}$ & $\begin{array}{l}53.2 \\
(0.044)\end{array}$ & 49.8 & $\begin{array}{l}50.7 \\
(0.262)\end{array}$ & 52.5 & $\begin{array}{l}59.9 \\
(0.092)\end{array}$ & 58.4 & $\begin{array}{l}61.8 \\
(.428)\end{array}$ & 61.4 & $\begin{array}{l}50.6 \\
(0.026)\end{array}$ & 44.8 \\
\hline
\end{tabular}

Adjusted percentages based on stratified probit model results, with discordant patients as the reference category. Model adjusted for patient age, gender, preferred language, number of comorbidities, \# of primary care visits in 2005, Medicare status, \# of medication classes taken for condition, pill burden, geocoded education and income, physician age, gender, race, language, panel size and \# of diabetic patients in panel. Patient-physician Spanish language concordance was defined as the patient reporting Spanish as the primary language spoken and the physician reporting Spanish language fluency. 
of better patient-physician communication and reduced language barriers or because language may be a proxy for the patients' level of acculturation. It is possible that less acculturated patients are more likely to benefit from concordance.

Our results suggest a modest association between race/ ethnicity concordance and treatment adherence for African American patients. Race/ethnicity concordance for African American patients was significantly associated with improved adherence to CVD medications. A long history of discrimination, legal and de facto segregation in the United States health care system, infamous medical trials (e.g. The Tuskegee Syphilis trials) and under-representation of racial and ethnic minority groups in health care professions present unique challenges to the patient-physician relationship for African American patients. ${ }^{16,34}$ African American patients, then, may be more likely to benefit from racially concordant patientprovider relationships, insofar as these relationships alleviate barriers to the patient-physician relationship.

While this study is the first to examine the association of race/ethnicity and language concordance with adherence to cardiovascular medications for a large cohort of patients with diabetes, a few limitations of the study should be noted. First, as an observational study, we were unable to randomly assign patients to treatment and control groups. Unobserved factors correlated with adherence may have influenced the selection of a same race, ethnicity or language physician. Second, while race/ethnicity may be an approximate proxy for cultural concordance, a great deal of diversity exists within each racial/ethnic and linguistic group. Third, patients and physicians were from a single large, integrated healthcare delivery system; it is possible that patients and physicians in this setting may be different from patients and physicians in other settings. Based on previous research comparing insured and uninsured patients ${ }^{33}$, we hypothesize that patients in this study were less likely to be very low income or have very low levels of education. Adherence and the impact of concordance may very well differ in the more general population.

Although we adjusted for a comprehensive set of variables, we were limited by the fact that we only had access to socioeconomic status indicators from geo-coding; individual-level data on education and income were not available in this study. Our language variable was limited in that we have no measure for English proficiency. We also have no direct measure of health literacy, immigrant status and level of acculturation, all potentially important predictors of medication adherence. Another potential concern is that our measurement of adherence does not include adherence to other treatment recommendations, such as diet, exercise and other lifestyle changes. In addition, patients with diabetes receive care from several health professionals (e.g. pharmacists, nutritionists, nurse practitioners, etc). We were unable to assess patient concordance with medical staff and these relationships may have played a role in predicting adherence. We hypothesize that we underestimate the impact of concordance because patients in this system are seen by several physicians, depending on their particular needs.

\section{CONCLUSION}

Race/ethnicity and language concordance were modestly associated with improved medication adherence for African American and Spanish-speaking Hispanic patients, suggesting that efforts to improve opportunities for concordance such as race/ethnicity based recruitment and retention efforts could reduce disparities in medication adherence. Reducing medication adherence disparities can ultimately improve health outcomes and reduce disparities for African American and Spanish-speaking Hispanic patients. Future research to examine the particular aspects of the concordant patientphysician relationship that make a difference can inform efforts to reduce disparities in medication management.

By increasing the opportunity for race/ethnicity and language concordance for patients for whom concordance would make a difference, efforts to diversify the medical workforce can have an important impact on public health.

Acknowledgements: This study was jointly funded by Program Announcement number 04005 from the Centers for Disease Control and Prevention (Division of Diabetes Translation) and the National Institute of Diabetes and Digestive and Kidney Diseases. Support was also provided by the Agency for Healthcare Research and Quality and the National Institute of Aging (RO1HSO13902-01) and NIA (R01-AG029316-01). The findings and conclusions in this report are those of the authors and do not necessarily represent the views of the funding organizations. Dr. Schmittdiel is supported by the Office of Research in Women's Health Building Interdisciplinary Careers in Women's Health K12 Career Development Award (K12HD052163). Dr. Mangione is partially supported by the UCLA Resource Center for Minority Aging Research (NIA \#2P3OAG021684O6), and by the UCLA/Drew Project EXPORT, National Institutes of Health, National Center on Minority Health \& Health Disparities (P2OMDO00148/P2OMDO00182).

\section{Conflict of Interest: None disclosed.}

Open Access: This article is distributed under the terms of the Creative Commons Attribution Noncommercial License which permits any noncommercial use, distribution, and reproduction in any medium, provided the original author(s) and source are credited.

Corresponding Author: Ana H. Traylor, MPP; Care Management Institute, Kaiser Permanente, 1 Kaiser Plaza, 16L, Oakland, CA 94612, USA (e-mail: Ana.h.traylor@kp.org).

\section{REFERENCES}

1. Grundy SM, Benjamin IJ, Burke GL, et al. Diabetes and cardiovascular disease: A statement for healthcare professionals from the American Heart Association. Circulation. 1999;100:1134-46.

2. Smedley BD, Stith AY, Nelson AR. Unequal treatment: confronting racial and ethnic disparities in health care. Washington DC: National Academy Press; 2002.

3. Munger MA, Van Tassel BW, LaFleur J. Medication nonadherence: an unrecognized cardiovascular risk factor. MedGenMed. 2007;9:58.

4. Gellad WF, Haas JS, Safran DG. Race/Ethnicity and nonadherence to prescription medications among seniors: results of a national study. J Gen Intern Med. 2007;22:1572-8.

5. Sclar DA, Robison LM, Skaer TL, Dickson WM, Kozma CM, Reeder CE. Sulfonylurea pharmacotherapy regimen adherence in a Medicaid population: influence of age, gender, and race. Diab Educ. 1999;25:5318.

6. Benner JS, Glynn RJ, Mogun H, Neumann PJ, Weinstein MC, Avorn J. Long-term persistence in use of statin therapy in elderly patients. JAMA. 2002;288:455-61.

7. Osterberg L, Blaschke T. Adherence to medication. N Engl J Med. 2005;353:487-97.

8. Cooper LA, Roter DL, Johnson RL, et al. Patient-centered communication, ratings of care, and concordance of patient and physician race. Ann Intern Med. 2003;139:907-15. 
9. van Ryn M. Research on the provider contribution to race/ethnicity disparities in medical care. Med Care. 2002;4:140-51.

10. Johnson RL, Roter D, Powe NR, et al. Patient race/ethnicity and quality of patient-physician communication during medical visits. Am J Public Health. 2004;94:2084-90.

11. vanRyn M, Burke $\mathbf{K}$. The effect of patient race and socioeconomic status on physicians perceptions of patients. Soc Sci Med. 2000;50 (6):813-28.

12. Malat J. Social distance and patients' rating of healthcare providers. J Health Soc Behav. 2001;42:360-72.

13. Altice FL, Mostashari F, Friedland GH. Trust and acceptance of and adherence to Antiretroviral Therapy. J Acquir Immune Defic Syndr. 2001:28:47-58.

14. Ciechanowski PS, Katon WJ, Russo JE, et al. The Patient-provider relationship: attachment theory and adherence to treatment in diabetes. Am J Psychiatry. 2001;158:29-35

15. Boulware LE, Cooper LS, Ratner LE, et al. Race and trust in the health care system. Public Health Rep. 2003;67:358-65.

16. Gamble V. A legacy of distrust: African Americans and medical research. Am J Prev Med. 1993;9:S35-8.

17. Chen FM, Fryer GE Jr, Phillips RL Jr, et al. Patients beleifs about racism, preferences for physician race and statisfaction with care. Ann Fam Med. 2005;3:138-43.

18. Johnson RL, Saha S, Arbelaez JJ, et al. Racial and ethnic differences in patient perceptions of bias and cultural competence in health care. $\mathrm{J}$ Gen Intern Med. 2004;19:101-10.

19. Blanchard J, Nayar S, Lurie N. Patient-provider and patient-staff racial concordance and perceptions of mistreatment in the health care setting. J Gen Intern Med. 2007;22:1184-9.

20. Saha S, Arbelaez JJ, Cooper LA. Patient-physician relationships and racial disparities in the quality of health care. Am J Public Health. 2003;93:1713-9.

21. Brach C, Fraser I. Can culturally competency reduce racial and ethnic disparities? A review and conceptual model. Med Care Res Rev. 2000;57:181-217.

22. Saha S, Shipman S. The Rationale for diversity in the health professions: A review of the evidence. [HRSA web sitel October 2006. Available at: http://bhpr.hrsa.gov/healthworkforce/reports/diversity/default. htm. Accessed date: 03/31/2010.

23. LaVeist TA, Nuru-Jeter A. Is doctor-patient race concordance associated with greater satisfaction with care? J Health Soc Behav. 2002;43:296306.

24. Saha S, Komaromy M, Koepsell TD, Bindman AB. Patient-physician Racial Concordance and the Perceived Quality and Use of Health Care. Arch Intern Med. 1999;159:997-1004.

25. LaVeist TA, Nuru-Jeter A, Jones KE. The association of doctor-patient race concordance with health services utilization. J Public Health Policy. 2003;24:312-23.

26. Howard DL, Konrad TR, Stevens C, et al. Physician-patient racial matching, effectiveness of care, use of services, and patient satisfaction. Res Aging. 2001;23:83-10.

27. Manson A. Language concordance as a determinant of patient compliance and emergency room use in patients with asthma. Med Care. 1988;26:1119-28.

28. Pérez-stable EJ, Nápoles-Springer A, Miramontes JM. The effects of ethnicity and language on medical outcomes of patients with hypertension or diabetes. Med Care. 1997;35:1212-9.

29. Schmittdiel JA, Uratsu CS, Karter AJ, et al. Why don't diabetes patients achieve recommended risk factor targets? Poor adherence versus lack of treatment intensification. J Gen Intern Med. 2008;23: 588-94.
30. Gordon NP. How Does the Adult Kaiser Permanente Membership in Northern California Compare with the Larger Community? Oakland, CA: Kaiser Permanente Division of Research; 2006 June. Available at: www. dor.kaiser.org/external/uploadedFiles/content/research/mhs/Other Reports/comparison_kaiser_vs_nonKaiser_adults_kpnc.pdf. Accessed date: 03/31/2010.

31. Steiner JF, Prochazka AV. The assessment of refill compliance using pharmacy records: methods, validity, and applications. J Clin Epidemiol. 1997;50:105-16.

32. Kressin NR, Wang F, Long $\mathbf{J}$, et al. Hypertensive patients' race, health beliefs, process of care, and medication adherence. J Gen Intern Med. 2007;22:768-74

33. Piette JD, Wagner TH, Potter MB, Schillinger D. Health insurance status, cost related medication underuse and outcomes among diabetes patients in three systems of care. Med Care. 2004;42:102-9.

34. Tatum BD. Why are all the black kids sitting together in the cafeteria? And other conversations about race. New York: Basic Books; 1997, 2003.

\section{APPENDIX. DIAGNOSTIC CRITERIA FOR DIABETES MELLITUS, HYPERTENSION, AND DYSLIPIDEMIA}

\section{Diabetes Mellitus (one of the following):}

1) At least one prescription of insulin or an oral hypoglycemic agent; or

2) At least two outpatient diagnoses of diabetes mellitus; or

3) One outpatient diagnosis of diabetes mellitus plus $>1 \mathrm{Hb}$ Alc $\geq 7 \%$; or

4) At least one hospital discharge with a primary DM-related diagnosis (ICD-9 code 250.X).

\section{Hypertension (one of the following):}

1) At least one prescription for an anti-hypertensive medication plus an outpatient diagnosis of hypertension; or

2) At least two outpatient diagnoses of hypertension; or

3) At least one prescription for an anti-hypertensive medication plus one or more elevated outpatient blood pressure readings ( $\geq 130 \mathrm{~mm} \mathrm{Hg}$ systolic, or $\geq 85 \mathrm{~mm} \mathrm{Hg}$ diastolic); or

4) At least one outpatient diagnosis of hypertension plus at least one blood pressure reading of $\geq 130 \mathrm{~mm} \mathrm{Hg}$ systolic or $\geq 85 \mathrm{~mm} \mathrm{Hg}$ diastolic;

\section{Dyslipidemia (one of the following):}

1) At least one prescription for an anti-lipemic agent; or

2) Outpatient diagnosis of hyperlipidemia/hypercholesterolemia with an LDL-cholesterol value $\geq 100$; or

3) Outpatient diagnosis of hyperlipidemia/hypercholesterolemia with a prior LDL-cholesterol value $\geq 100$ (within 2 years prior to $7 / 01 / 00$ ). 